\title{
A bordo do República: diário pessoal da expedição de Oswaldo Cruz aos portos maritimos e fluviais do Brasil
}

1 Infehzmente, não encontramos os relatónos oficiais da expedição que Oswaldo Cruz deve ter enviado ao ministro da Justıça e Negócios Interiores, dr J J Scabra.

$\mathrm{E}$ ntre setembro de 1905 e fevereiro de 1906, no auge da remodelação urbana e do saneamento do Rio de Janeiro, Oswaldo Cruz iniciou uma longa viagem de inspeção aos portos marítimos e fluviais do Norte e do Sul do Brasil, com o objetivo de levantar dados para instruir o projeto de reforma da organização sanitária dos mesmos. O esmagamento da Revolta da Vacina, dez meses antes, não silenciara as controvérsias que envolviam tanto as campanhas sanitárias do diretor-geral de Saúde Pública quanto as demolições promovidas pelo prefeito Pereira Passos e pelas comissões federais que superintendiam a abertura da avenida Central e as obras do porto na capital federal.

A expedição de Oswaldo Cruz foi mais um fato a dividir as opiniões na cidade, opondo, de um lado, os que a consideravam uma viagem turística fora de propósito, e, de outro, os que enalteciam a expedição que iria redimir outros centros portuários do país das mazelas que eram suprimidas no Rio.

Embora os artigos publicados na imprensa, os relatórios da Diretoria Geral de Saúde Pública (DGSP) e as cópias de telegramas oficiais enviados às autoridades de cada porto sejam fontes importantes para a investigação deste episódio, ${ }^{\prime}$ o conjunto documental que desejo colocar em evidência é a correspondência pessoal entre Oswaldo Cruz e sua esposa, Emília Fonseca Cruz, a 
quem carinhosamente chamava de 'Miloquinha'. Trata-se de um grupo de 16 cartas, com datas-limite situadas entre 28 de setembro e 7 de novembro de 1905, em que o missivista se propõe a fazer um diário detalhado dos acontecimentos vivenciados nos portos em que esteve. A série não está completa. A última carta disponível foi enviada de São Luís do Maranhão, mas sabemos que Oswaldo Cruz prosseguiu viagem até Manaus e, depois, aos portos do Sul. Ainda assim, o valor informativo desse grupo de documentos é inestimável. Além de registrar impressões sobre as condições de saúde reinantes nas cidades visitadas e sobre a arquitetura e topografia das mesmas, Oswaldo Cruz tece comentários a respeito dos hábitos e costumes de seus habitantes, seus modos de vestir e falar, observando atentamente o comportamento de personagens que ia conhecendo de porto em porto, fossem autoridades, membros das elites locais ou gente simples do povo.

Por se tratar de correspondência pessoal, é um testemunho despreocupado e informal, portanto mais sincero e afetivo, permitindo visualizar melhor que outros documentos o universo psicológico do autor. Esperamos que neste trabalho os leitores possam vislumbrar não só algumas das cenas que registrou no Norte do Brasil como também o ponto de vista subentendido nos descontraídos depoimentos à esposa.

O conjunto documental acha-se sob a guarda do Departamento de Arquivo e Documentação da Casa de Oswaldo Cruz/Fiocruz. Faz parte da série Correspondência do Fundo Oswaldo Cruz, o qual possui cerca de dois mil itens documentais de tipo textual, iconográfico e cartográfico, com datas-limite situadas entre 1885 e 1953. Aí está registrada, com considerável detalhe, a trajetória profissional, intelectual e administrativa do titular. A documentação referente ao tempo em que fez os estudos superiores e em que dirigiu o Instituto Oswaldo Cruz (IOC) e a DGSP compreende relatórios de expedições realizadas ao interior do país, fotografias, correspondência pessoal, administrativa e científica, protocolos de pesquisa, cadernos de anotações de aulas, recortes de jornais etc. O fundo percorre período maior que o tempo de vida do titular porque inclui homenagens póstumas e vasta documentação institucional ligada às atividades científicas do IOC. Merecem destaque os oito volumes encadernados de notícias, entrevistas e charges que trazem fatos, representações e perfis veiculados por vários jornais do país ao longo da vida pública do cientista, com concentração no período em que atuaram as brigadas de matamosquitos, e em que tentou implementar a vacinação obrigatória contra a varíola. Estes volumes têm como datas-limite os anos de 1903 e 1915. Um nono volume, referente ao ano de 1917, contém notícias relativas à morte do cientista e às homenagens póstumas que recebeu. A documentação que compõe o Fundo Oswaldo 
2 Cabo frio, Vitóra, Caravelas, Porto Seguro, Santa Cruz, Salvador, Penedo, Aracaju, Maceió, Tamandaré, Recife, Cabedelo, Paraíba, Natal, Mossoró, Assu, Camocim, Fortaleza, Amarração, São Luís, Bclém, Santarém, Óbıdos, Parintins e Manaus (Guerra, 1940, P 326)
Cruz tem se revelado de grande relevância para os cientistas sociais que investigam a difusão da medicina experimental e os processos de elaboração e execução das políticas públicas de saúde no Brasil.

\section{A expedição}

Em 1903, o Brasil participou da Conferência Internacional de Paris, que reuniu os países signatários da Convenção de Veneza, ocorrida em 1897. Discutiram, na ocasião, os mais recentes estudos relativos à profilaxia da peste e do cólera. Por sugestão do representante brasileiro, o diplomata e médico Gabriel de Piza, foi incluída na pauta da conferência a profilaxia da febre amarela, a respeito da qual se pronunciaram o dr. Émile Roux, do Instituto Pasteur de Paris, e o dr. William Gorgas, da missão norte-americana em Cuba. Foi aceita, então, a tese da transmissão da doença pelo Stegomya fasciata, reconhecendo-se como legítimo o extermínio do mosquito transmissor, base da profilaxia que fora praticada em Havana, e que se instituía no Rio de Janeiro.

$\mathrm{Na}$ Conferência Internacional do Rio de Janeiro, realizada no ano seguinte, revogaram-se as medidas anteriormente adotadas para combater a febre amarela, sobretudo as quarentenas e a desinfecção dos doentes, e se votou a obrigatoriedade das medidas que Oswaldo Cruz implementava na capital federal.

Como signatário das convenções mencionadas, o Brasil se comprometeu, também, a promover a reformulação administrativa dos serviços de saúde de seus outros portos. No relatório enviado ao ministro J. J. Seabra, em 1905, Oswaldo Cruz (1905) alertou-o para a necessidade de protegê-los contra eventuais invasões da peste e do cólera: "Para darmos fiel cumprimento ao disposto nesses tratados é indispensável dotar, senão todos, ao menos os principais portos de instalações sanitárias necessárias para que se possa pôr em prática o isolamento dos contagiosos e rigorosa desinfecção não só dos navios como de todos os objetos e das pessoas capazes de veicular contágio. Em suma, é urgente a instalação de hospitais de isolamento e de estações de desinfecção nesses portos."

Em 27 de setembro de 1905, Oswaldo Cruz embarcou no vapor República, da DGSP, com seu secretário, o dr. João Pedroso Barreto, rumo ao Norte do país, com o objetivo de detalhar o plano de reorganização dos serviços de saúde operantes nesta parte do litoral. Visitaram 24 portos durante os 68 dias de viagem. ${ }^{2} \mathrm{O}$ diário detalhado dela para a esposa, Emília Fonseca Cruz, começa ainda na enseada de Botafogo, onde o navio permaneceu ancorado até o dia seguinte ao do embarque devido ao mau tempo que frustrou a primeira tentativa de deixar a baía de Guanabara. 
A carta à "querida Miloca", de que vamos transcrever alguns trechos, é a terceira do conjunto, escrita em 2 de outubro, no canal dos Abrolhos, porto de Caravelas, sul da Bahia.

..Às $12 \mathrm{~h}$ e 30 entrávamos à barra de Vitória, passando ao lado do farol de Moreno e junto ao lindo convento da Penha. Não podes imaginar que belo espetáculo se divisa então; o mar deita um braço de trezentos a quatrocentos metros de largura pelo interior da terra. Inúmeras ilhas verdejantes com belas edificações são dispostas, formando um belo canal, ao fundo do qual, e à direita de quem entra, está a cidade da Vitória, disposta em anfiteatro, pequena, iluminada pelo sol, cuja vista enche-me da mais justificada alegria porque, com a terra, vi cessarem os sofrimentos de enjôo, e, mais que isto, de soluço, que perseguia-me noite e dia.

Lançado ferro, foi o Repíblica cercado de embarcações: escaler do médico do porto, dr. Aguirre, escaler da polícia do porto, escaler do governador clo estado. ... Quase afônico e em completo jejum, desembarquei tão satisfeito como quem sai d'um cárcere. Visitamos em primeiro lugar a Inspetoria do Porto, clepois fomos ao palácio cumprimentar o governador, meu antigo conhecido, que me é devedor de alguns favores e que recebeu-me muito delicadamente, insistindo para que fosse morar no palácio, ao que não acedi; ofereceu-me entào champanha, que não aceitei porque estava em jejum. Visitamos a Inspetoria de Higiene Terrestre que está a cargo de um antigo colega de ano, um mulato pernóstico que, segundo ele mesmo disse-nos, não cuida senão de política e nunca vai à repartição. ...

Findo o jantar ... fiquei numa farmácia duma tia do Aguirre a conversar e indagar de tudo. A cidade está quase que em revolução: os espíritos estão agitadíssimos, o Congresso está contra o governador, manifestações percorrendo as ruas, discursos, manifestos etc., tudo isso extremamente cômico porque os mais acerbos adversários encontram-se na rua, conversam como dois bons amigos, indo depois para os jornais onde se descompòem como verdadeiros regateiros.

Passei depois a visitar a cidade: um verdadeiro chiqueiro; nào há a mínima higiene, não há esgotos, os despejos são feitos no mar por meio de barris, de modo que às $10 \mathrm{~h}$ da noite ninguém mais pode aproximar-se das praias. Não há água a não ser de uns poços imundos. Há perto da cidade duas fontes de boa água, mas onde para se colher uma lata de querosene são necessárias cerca de cinco horas!, e aincla assim são precisas (sic) três pessoas para proteger esta contra o ataque dos outros que estão à espera! As ruas sĩo vielas imundas que nunca são limpas, cheias de lixo, defecação de animais etc. etc. As casas estão esboroando-se, são de péssima construção, salvo um pequeno número de exceções. Há um teatro: um verdadeiro pardieiro, todo de madeira e (ilegível) pintado que dá pelo pomposo nome de Teatro Melpomene e que custou para mais de seiscentos contos de réis!!! Atualmente está no teatro uma dançarina, Stela Fallet, que faz a dança das serpentinas e que está fazendo uns benefícios a favor de instituições de cariclade, e, por isso, encontram-se nas ruas umas fiadas de 'sacarias' passando cartões para os tais espetáculos. O hospital é um horror! Fui visitar um colégio de irmàs de caridade e aí encontrei moribunda, afetada de tuberculose galopante. uma irmã de caridade que é irmã do Rego de Faria: contristou-me en extremo 
3 Peixe do Atlântico, de dorso cinzento tirante ao verdeazulado c abdome branco medindo até $4 \mathrm{~m}$ e pesando, às veres, mais de $300 \mathrm{~kg}$. Muito apreciado na pesca esportiva por sua valentia e tamanho, alimenta-se de outros peixes, inclusive caçoes, havendo lendas segundo as quais ataca a balcia. Tem a maxila prolongada $\mathrm{cm}$ forma de uma lâmina de espada cortante. o espetáculo, porque poucos dias antes a pobre moça nada apresentava de suspeito e, creio, não terá três dias de vida! ...

No dia seguinte ... eu passeava pela cidade 'tutudando' tudo. Às $8 \mathrm{~h} \mathrm{da}$ manhã tomamos uma lanchinha de gasolina que trazemos conosco e fomos visitar o Hospital de Isolamento, na ilha de Príncipe, uma verdadeira vergonha!, que custou um dinheiro surdo! Fomos depois ao Convento da Penha, construção secular situada no alto duma rocha sobre o mar: uma verdadeira beleza, hoje abandonada. Entretanto havia aí uma festa com Te Deum em ação de graças pelo salvamento dos passageiros e tripulantes dum vapor que soçobrara havia dias. Foi uma festa interessante e cheia da cor local, tendo podido estudar nela os hábitos dos espírito-santenses. Passeamos depois pela cidade de Espírito Santo, antiga Vila Velha, outrora capital de estado .... Consegui apanhar alguns mosquitos e larvas. No alto do morro da Penha, no convento a que acima aludi, encontrei um indivíduo com febre intermitente do qual consegui colher várias lâminas de sangue. Voltamos depois para Vitória, tendo visto alguns (ilegível) do Clube de Regatas e depois de ter tirado várias fotografias e de ter estudado as condições topográficas das ilhas existentes, a fim de ver qual a que se prestará para a instalação de um hospital de isolamento....

Às $3 \mathrm{~h}$ da tarde saímos de novo em demanda do porto de Caravelas. .... Caminhamos por perto dos terriveis Abrolhos porém pelo lado de terra e tão perto dela chegamos que encalhamos na lama donde já saímos e estamos parados à espera do prático que levará o navio até Caravelas, onde pretendemos presenciar um dos mais belos espetáculos da região: a pesca das baleias que constitui o principal comércio da região. Já temos encontrado vários destes cetáceos que passam ao largo, atirando altas colunas d'água e que fogem espavoridos diante dos espadartes, seu mais temível inimigo. ${ }^{3}$

Pretendemos dormir hoje em Caravelas, partindo amanhã de madrugada, talvez para Porto Seguro, a fim de vermos o monte Pascoal e o primeiro porto do Brasil a que chegou Cabral. ...

Do teu

Oswaldo

Ao longo de toda viagem, nosso herói se esforça para que a esposa veja através de seus olhos a paisagem que se descortina do navio e sinta com a mesma intensidade que ele as impressões suscitadas por aqueles lugares que pareciam tão remotos, exóticos e atrasados para os habitantes da capital que, a duras penas, ia se transformando na segunda réplica americana de Paris (a primeira, Buenos Aires, fora remodelada alguns anos antes).

As cartas subseqüentes de Oswaldo Cruz reúnem, em proporções similares, os juízos indignados do sanitarista, o relato das celebrações promovidas pelos figurões locais, observações sobre fenômenos e seres inventariados com curiosidade de naturalista, sobre paisagens admiradas com o embevecimento de um viajante comum e, ainda, a descrição de cenas e situações envolvendo grupos e figuras humanas que provocam no viajante espanto, gozo e, às vezes, profunda compaixão. É o caso, por exemplo, do 
FONTES

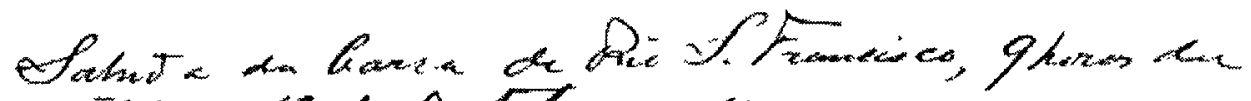
- sente de 13 de Qutaba de 490.

Quanida bin thiber

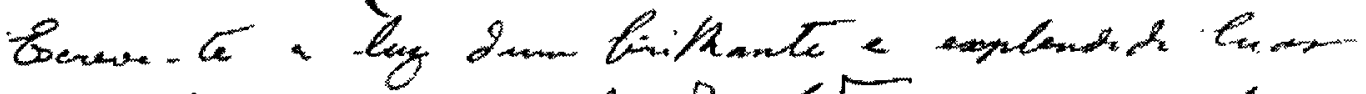

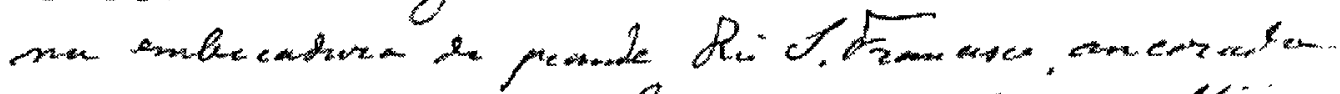

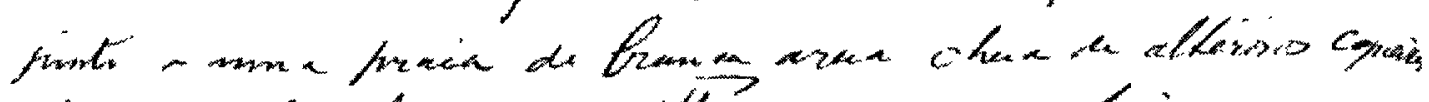

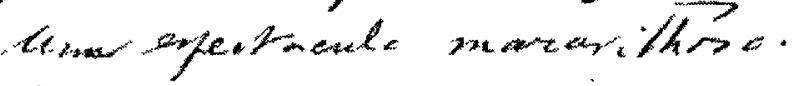

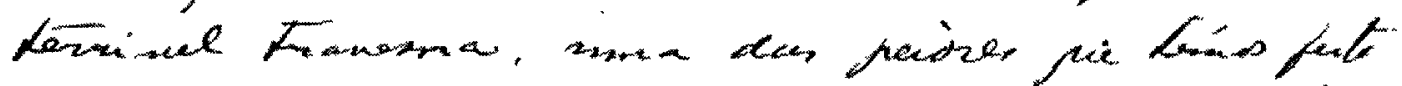

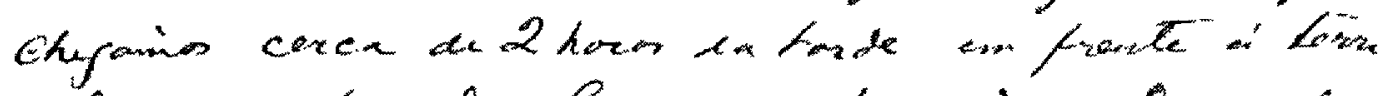

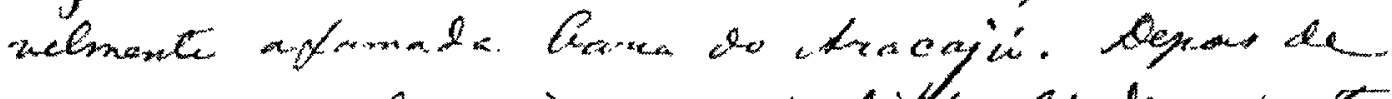

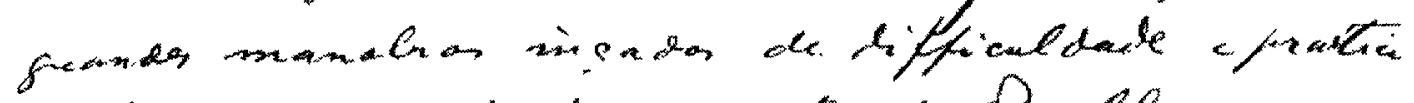

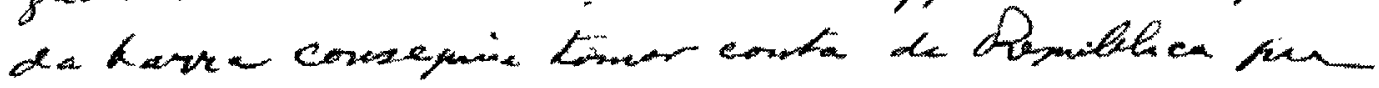

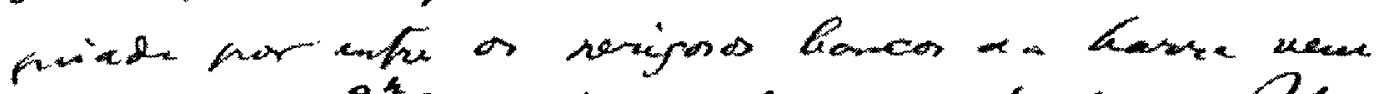

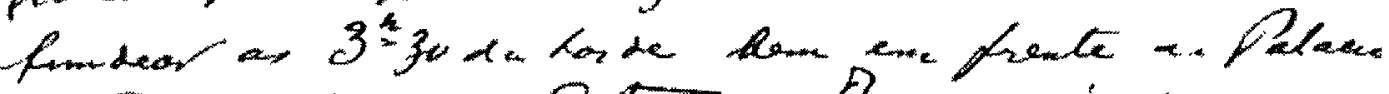

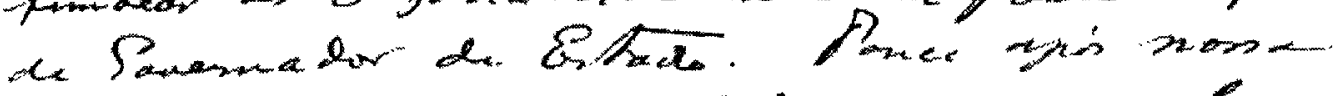

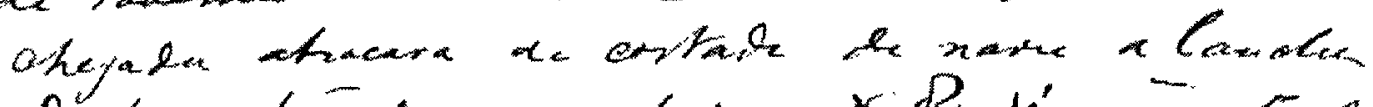

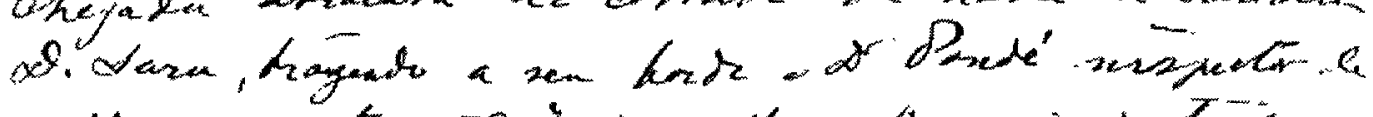

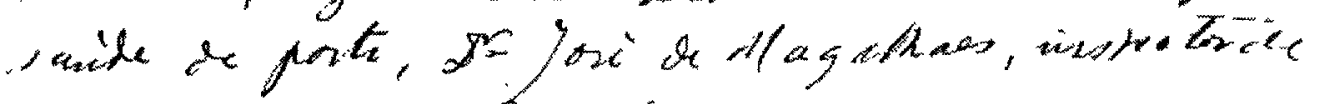

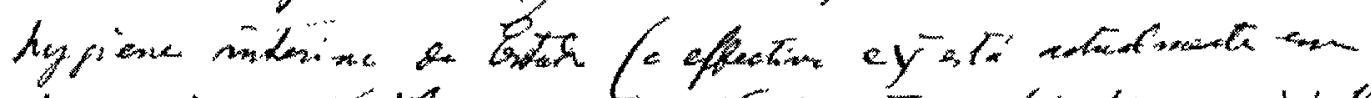

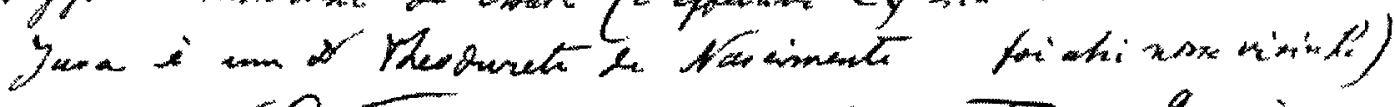

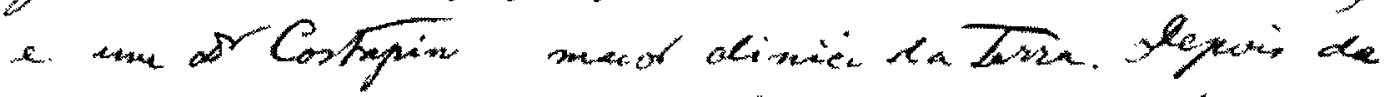

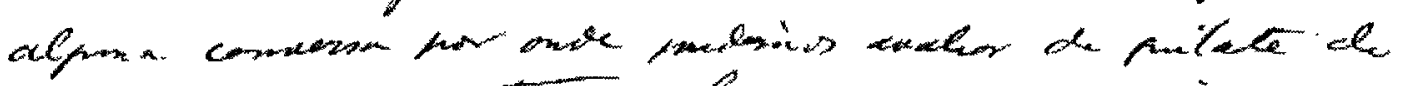

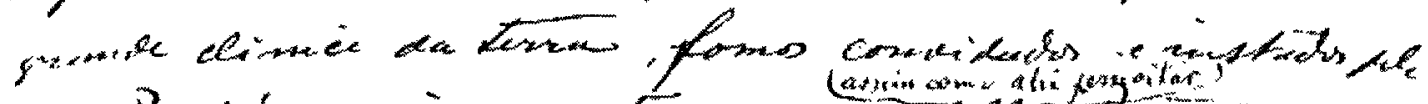

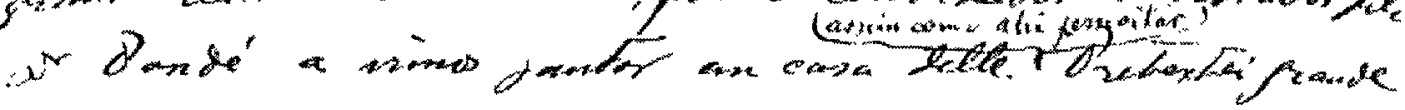

Fac-símile de carta de Oswaldo Cruz à 'Miloca'.

164 HISTÓRIA, CIÊNCIAS, SAÚDE Vol. IV (1) 
'orgueiro', menino de Aracaju que reproduzira o órgão de uma igreja com tubos de bambu e arame roubado de cercas, e que tocava o instrumento intuitivamente, apesar de ser analfabeto. Comovido com a apresentação, Oswaldo Cruz prometeu levá-lo para o Rio, a fim de que pudesse aprender música e receber instrução escolar. O fato é narrado no sétimo documento do conjunto epistolar, escrito na saída da barra do rio São Francisco, em 13 de outubro. Leiamos trechos dele que bem ilustram a riqueza informativa da correspondência pessoal.

Guiado por um prático muito hábil, o República transpõe a perigosa barra de Aracaju e sobe o São Francisco até Penedo, capital do sertão alagoano. A princípio, o navio joga violentamente, e Oswaldo Cruz é todo um torturante, angustioso enjôo. Vencidas as águas revoltas da foz do velho Chico, o navio engrena um curso sereno, silencioso, e o viajante pode, de novo, se deleitar com as paisagens que descortina do tombadilho.

...Nas margens, grandes coqueirais, plantios de cana-de-açúcar, baixios com sopé - pequenas povoações, ruínas atestando as devastações das grandes enchentes. De quando em vez, semelhando uma borboleta gigantesca abrindo duas grandes asas alvas, singravam o rio as grandes 'canoas abertas' do São Francisco, tendo à proa um pequeno camarote coberto de folhas de coqueiro, onde, estirado numa rede, o marujo desferindo plangentes endechas faz dormir seus companheiros ao som do violão e à luz pálida e melancólica do luar do sertão. Subíamos lenta mas alegremente, e às $4 \mathrm{~h}$ lançamos ferro em frente a Penedo ... . Não imaginas o que nos esperava! A população toda aglomerada na praia parecia um enorme enxame de abelhas. Na ponte, iluminados pelos raios oblíquos do sol poente, víamos o reluzir de instrumentos metálicos e galões dourados: era a filarmônica da terra que nos aguardava. Breve desatraca da ponte uma lancha, a Consuelo, apinhada de gente que, fazendo voltas ao redor do República, veio afinal atracar à escada. Era um deputado meu antigo conhecido, dr. Raimundo de Miranda, que com os maiores da terra vinha receber-me. Depois dos cumprimentos etc., fui convidado a descer. Quis pretextar qualquer coisa para evitar o papelão de me apresentar em terra, mas foi debalde, e, para não molestar o deputado que me tinha declarado ter movimentado toda sua gente para receber-me, fui para terra, sendo aclamado ao desembarque pelo povo e seguido a pé acompanhado pela charanga e pela massa popular até a residência do delegado de Saúde do porto, o dr. Hermínio de Freitas Melro, onde ser-meia oferecido um jantar. Depois de ter recebido algumas centenas de abraços (este povo de Alagoas tem uma colossal predileção pelos abraços), fui jantar. Muita comida! Tudo muito burguês! O dr. Melro, um cabrocha todo empertigado, o dr. Patury, com cara de feto, com dentes postiços mal colocados, o dr. Sócrates, um velho septuagenário surdo, o dr. Miranda, o deputado, radiante com o sucesso da manifestação, não tirava o charuto da boca e agitava em desopilantes risadas seu colossal e prematuro abdome que atingiu já o mais completo desenvolvimento aos 37 anos de idade. Eram estes os convivas que conhecia, além do grande Pedroso. Outros havia, 
verdadeiros 'endomingados' que há muito não comiam peru e outras iguarias finas de banquete. Terminado o jantar, fizemos umas estiradas a pé pela cidade, visitamos o hospital e às $8 \mathrm{~h}$ retiramo-nos para bordo, não tendo aceito o convite que nos foi feito para dormirmos em terra, e depois de termos passado pela casa do deputado, que se achava cercado de numerosos 'cafajestes' eleitorais numa casa mal arejada e tresandando a fumo. A noite estava luarenta, linda; nas margens do rio, os pescadores entoavam, ao som do violão, sentidas cantigas, as águas marulhavam docemente junto ao costado do República; triste, extremamente saudoso, tomei da pena para terminar sua carta que começo a dirigir-te. Adormeci.

Não é o único documento onde se nota a aversão do autor pelos potentados locais e seus capachos. Ao elogiar a firmeza de caráter de algum político, faz questão de realçar a excepcionalidade dessa virtude. Os resquícios ainda evidentes do regime escravista causam indignação naquele homem que é recebido como o medalhão da capital federal. Por outro lado, é com uma atitude sempre paternalista, superior, que se refere às classes populares, que encara como passivas vítimas da dominação oligárquica e do atraso cultural. À exceção, talvez, de Aracaju, cujo governador elogia, todas as localidades visitadas no litoral Norte acham-se em estado deplorável de abandono, sem sistema de esgoto, sem água encanada, nenhum planejamento urbano, assistência médica e serviços sanitários inexistentes ou de eficácia nula.

Os registros disponíveis no Arquivo Oswaldo Cruz cessam no porto de São Luís do Maranhão. O autor declara aí intenção de prosseguir o detalhado diário, e tudo leva a crer que o fez, até ancorar de novo no Rio de Janeiro, à bordo do paquete Santos, em 28 de janeiro de 1906. A expedição só terminou em 28 de fevereiro, após a visita aos portos do Sul, mas para esta segunda etapa não há mais nenhum registro epistolar. Sabe-se, apenas, que a bordo do paquete Aragon trouxe grande quantidade de material para pesquisa, principalmente sangue colhido de doentes e mosquitos de diversas procedências, que constituíram os primeiros insumos usados para traçar o quadro de saúde vigente nos 'sertões' do Brasil, episódio que só seria concluído pelo esforço coletivo de outros cientistas do IOC, uma década depois.

\author{
Ana Luce Girão Soares de Lima \\ Departamento de Arquivo e Documentação \\ Casa de Oswaldo Cruz/Fiocruz \\ Avenida Brasil, 4036, $6^{\circ}$ andar \\ 21040-361 Rio de Janeiro - RJ Brasil
}


A BORDO DO REPÚBLICA

\section{FONTES}

Manuscritas

Arquivo Oswaldo Cruz - Série Correspondência

Impressas

Cruz, Oswaldo. Relatório apresentado ao Exmo. Sr. Dr. J. J. Seabra, ministro da Justiça e Negócios Interiores, pelo dr. Oswaldo Cruz, diretor da Diretoria Geral de Saúde Püblica. Rio de Janeiro, Imprensa Nacional, 1905.

Cruz, Oswaldo. Relatório apresentado ao Exmo. Sr. Dr. J. J. Seabra, ministro da Justiça e Negócios Interiores, pelo dr. Oswaldo Cruz, diretor da Diretoria Geral de Saúde Pública. Rio de Janeiro, Imprensa Nacional, 1906.

Material disponível no Departamento de Arquivo e Documentação da Casa de Oswaldo Cruz (DADCOC/Fiocruz).

\section{REFERÊNCIAS BIBLIOGRÁFICAS}

Benchimol,

Jaime L. (org.)

1990

Guerra, E. Salles

1940

Oliveira, Otávio G. de 1955

Roche, Daniel jan.-fev. 1971

Schwartzman, Simon 1979

Stepan, Nancy 1976

Trébitsch, Michel mai. 1992

Chagas, Carlos;

Neiva, Arthur;

Penna, Belisário et alii.

1972
Manguinbos do sonbo à vida: a ciência na Belle Époque. Rio de Janeiro, Casa de Oswaldo Cruz/Fiocruz.

Oswaldo Criz.

Rio de Janeiro, Vecchi.

Oswaldo Cruz e suas atividades na direção da Saúde Püblica brasileira. Rio de Janeiro, IBGE.

'Les primitifs du Rousseauisme: une analyse sociologique et quantitative de la correspondance de J.-J. Rousseau'. Em Annales: économie, société, civilisations. Paris.

Formação da comunidade científica no Brasil. São Paulo, Ed. Nacional.

Gênese e evolução da ciência brasileira: Oswaldo Cruz e a política de investigação científica e médica. Rio de Janeiro, Artenova.

'Correspondence d'intellectuels: le cas des lettres d'Henri Lefebvre à Norbert Guterman (1935-47)' . Em Cabiers de l'Institut du Temps Présent. Paris, $\mathrm{n}^{\mathcal{Q}} 20$.

Oswaldo Cruz no julgamento dos contemporâneos. Rio de Janeiro, UFRJ/FGV. 